\title{
El Arzobispo D. Martín de Ascargorta (1693-1719) y su mecenazgo al servicio del triunfo de la fe. El retablo del triunfo de Santiago de la Catedral de Granada
}

\author{
IgnaCio Nicolás LóPEZ-MuÑoz MartínEZ ${ }^{1}$
}

\section{Sumario:}

El arzobispo D. Martín de Ascargorta ha trascendido a la Historia del Arte como uno de los más relevantes mecenas en la Granada barroca de las postrimerías del siglo XVII. Dicho mecenazgo no es arbitrario sino que responde a una intencionalidad teológica meridiana: la vindicación del triunfo de la Fe. Armonizado con el contexto original siloesco de la Catedral de Granada, el retablo del Triunfo de Santiago o de la Fe, promovido por Ascargorta, se erige como síntesis plástica de los principales axiomas que definen el pensamiento y el mecenazgo ascargortianos. Desde un compromiso netamente trentino, Ascargorta asimila el pasado paleocristiano de Granada y lo redefine desde los códigos de la Reforma católica, donde la idea de triunfo es prevalente sobre el pecado -representado tanto en la "herejía mahometana"-. Este postulado es aplicado por el prelado en la defensa inmaculista de la Virgen, misterio criticado por los reformistas y que Ascargorta vindica a través de su mecenazgo, como proclama del ministerio soteriológico de María.

\section{Palabras clave:}

Historia de la Iglesia, Historia del Arte, Mecenazgo.
The archbishop Mrs. Martín de Ascargorta (1693-1719) and his patronage for the triumph of Faith. The Triumph of Santiago altarpiece of the Cathedral of Granada

\begin{abstract}
:
Archbishop Mrs. Martín de Ascargorta has transcended the History of Art as one of the most important patrons in baroque Granada in the late seventeenth century. This patronage is not arbitrary but responds to a manifest theological intentionality: the vindication of the triumph of the Faith. Related to the original siloesco context of the Cathedral of Granada, the altarpiece of the Triumph of Santiago or the Faith, promoted by Ascargorta, It stands as a plastic synthesis of the main ideas that define ascargortian thought and patronage. From a purely Trentinian commitment, Ascargorta assimilates the early Christian past of Granada and redefines it from the codes of the Catholic Reformation, where the idea of triumph prevails over sin -represented so much in the "Mohammedan heresy"-. This postulate is applied by the prelate in the Immaculate defense of the Virgin, a mystery criticized by the reformers and that Ascargorta vindicates through his patronage, as a proclamation of the soteriological ministry of Mary.
\end{abstract}

\section{Keywords:}

History of Catholic Church, History of Art, Patronage.

${ }^{1}$ Grupo de investigación HUM 362 de la Universidad de Granada. https://orcid.org/0000-00027410-9469<ignacion.lopezmunoz.edu@juntadeandalucia.es> 
Probablemente condicionado por unas propicias circunstancias económicas, el siglo XVII fue una etapa especialmente proclive al mecenazgo artístico por parte de diferentes estamentos sociales. En el caso del patrimonio eclesiástico no solo la propia tesorería diocesana sino también los beneficiados, la feligresía, las Hermandades y Cofradías, y por supuesto los representantes de la jerarquía eclesiástica contribuyeron con su mecenazgo a la eclosión del Barroco ${ }^{2}$. El siglo XVII significa la conjura de las artes al servicio del poder y de la $\mathrm{Fe}$, que ahora actúan como vehículos plásticos de transmisión de los principales misterios religiosos pero además de complejos idearios políticos y teológicos, tantas veces interrelacionados. Granada es un preclaro manifiesto de ese Arte del poder: efímera capital imperial, reino definitivo para la formación moderna de España y ciudad elegida por los Reyes Católicos para su enterramiento son notables circunstancias que posibilitan la creación de un Arte de Estado, precisamente en un contexto de reivindicación del pasado cristiano de una ciudad siete siglos musulmana. El siglo XVII también es para Granada, desde un punto de vista político y económico, el siglo del desencanto: la decadencia del imperio español se hace evidente en una ciudad que había despertado de su sueño imperial pero que mantiene el arrojo suficiente para testimoniar a la Historia principales hitos de la arquitectura, la pintura y la escultura. La llegada a la sede arzobispal del cordobés don Martín de Ascargorta (1693-1719), procedente de la diócesis salmantina, supone un desafío al declive granadino y el impulso determinante para la definitiva consolidación de gran parte del Patrimonio artístico de su Iglesia ${ }^{3}$. El arzobispo don Martín de Ascargorta ejerce un patrocinio no solo en la propia Catedral sino también en instituciones especialmente relevantes en su carrera eclesiástica y en la historia de Granada, como el Sacromonte, el Convento del Santo Ángel Custodio, donde tenía dos sobrinas monjas -hijas de su hermano Luis de Ascargorta-, o el Colegio de la Asunción de Córdoba. Su generoso mecenazgo trasciende a otras iglesias de la capital como la Colegial del Salvador $^{4}$ e incluso a la Capilla Real y de la provincia, especialmente en Loja,

${ }^{2}$ López-Guadalupe Muñoz, J. J.: "El mecenazgo artístico en la Granada del siglo XVIII. La financiación del Arte religioso". En: Revista del Centro de Estudios Históricos de Granada y su Reino, n. 10-11. Granada: CEHGR, 1996-1997, pp. 329-332.

${ }^{3}$ Gómez Román, A. M.: "Promoción y mecenazgo artístico del arzobispado de Granada durante el siglo XVIII". Cortés PeÑA, A. L.: Estudios sobre Iglesia y Sociedad en Andalucía en la Edad Moderna. Granada: Universidad, 1999, pp. 445- 452.

${ }^{4}$ El panegirista Gómez de Vega menciona que para la Colegial del Salvador "dio un terno de tela, que su valor se reputa en cinco mil reales, un cáliz sobredorado que costó mil y quinientos, tres sillas de terciopelo, de valor de quinientos reales. Para blanquear la Iglesia y acabar dos canceles, quatro mil reales, y cinco casullas, que importan dos mil reales". Gómez de Vega y Montalvo, C.: 
las Alpujarras -esta intervención evidencia el compromiso de Ascargorta en la cristianización de la zona más islamizada de la archidiócesis- y Motril ${ }^{5}$. El mecenazgo de Ascargorta en la transición al siglo XVIII supone la conjuración de todo un complejo ardid ideológico, de raíces reformistas católicas, donde a través de las imágenes representadas en retablos, lienzos y esculturas el Arte se sitúa inmerso en un programa de piedad y exaltación del mensaje de Trento, y actúa a favor de la proclamación del axioma esencial ascargortiano: el Triumphus Fidei.

Granada, último territorio "infiel" ganado a la causa católica, será por ende un símbolo en la culminación del ideal de Universitas Christiana de Carlos V. En el arzobispo Ascargorta se aúnan diversos componentes que hacen de su presencia, en los albores del siglo XVIII, un epítome humanista donde se sintetizan los axiomas del Concilio de Trento y la asimilación de una herencia imperial, ejemplificada en la Catedral de Granada.

La expresión plástica más representativa de la teología del arzobispo Ascargorta está declarada en, acaso, su obra más simbólica: el retablo del Triunfo de Santiago o de la Fe de la Catedral granadina. A partir de una premeditada disposición de obras preexistentes D. Martín de Ascargorta diseña esta máquina barroca que articula un discurso cuya máxima primordial será la vindicación del Triumphus Fidei, idea fundamental en la doctrina ascargortiana. Dicha Fe invicta se va a organizar desde dos postulados básicos: la rehabilitación historicista de la Iglesia paleocristiana granadina representada por su primer obispo, el mártir y legendario S. Cecilio, discípulo de Santiago, y el también prelado de esa primitiva diócesis S. Gregorio de Iliberri, teólogo de la Fe del siglo IV; y la epifanía del triunfo de la Fe sobre el pecado, expresada en la iconografía del ático y simbolizada expresamente en la Inmaculada Concepción.

La existencia previa de cuatro de las siete obras a partir de las que se articula el programa iconográfico y simbólico del retablo (Virgen del Pópulo o de los Perdones, Santiago, San Cecilio e Inmaculada) no ha de llevarnos a considerar una adaptación expresa de tal programa a dichas creaciones, sino que éstas van a responder con total entidad a la teología que ilumina el diseño

Panegírico historial de la vida y virtudes del Ilmo. Señor Don Martín de Ascargorta. Madrid: Imp. Gregorio Hermosilla, 1722, pp. 39-40.

${ }^{5}$ El mecenazgo de Ascargorta va más allá del ámbito local, registrándose su patrocinio también en iglesias de la archidiócesis como Víznar, Motril y Loja, o Almócita y Bubión en la Alpujarra. Así, el 17 de julio de 1702 don Martín de Ascargorta concede autorización para la realización de una capilla en el Santuario de la Cabeza de Motril por Francisco Villanueva. A. H. D. G. Libro minutario de cartas. Libros Archivo. Caja 24 (1).

A la Iglesia mayor de Loja "ayudó para su continuación, tiempo de nueve años, con nueve mil y seiscientos reales cada uno”. GómeZ DE VEGA, C.: Op. cit., p. 40. 
de este emblema plástico, donde cada una de las obras cobra valor per se y en cuanto a su interrelación contextual. De esta manera, la Inmaculada Concepción que centra el ático se alza como culmen definitivo del axioma ideológico del retablo, el Triumphus Fidei. Ascargorta expresa así en esta magna obra de su mecenazgo el principio primordial de su pontificado, coincidente con el concepto áulico siloesco de la Catedral misma, y que explicita su conocimiento de la Escolástica, especialmente del pensamiento del franciscano Juan Duns Scoto, cuya cátedra en la Universidad de Granada ostenta el prelado desde 1660. Frente a la tradición escolástica tomista, vindicadora de la purificación de la Madre de Cristo a posteriori de la asunción del pecado original, Scoto defenderá la exención de pecado en María desde el preciso instante de su concepción, siendo uno de los teólogos pioneros en la defensa del dogma inmaculista ${ }^{6}$. La Fe invicta que prevalece sobre el pecado queda subliminal y expresamente subrayada con la presencia de la Purísima, culmen sintético y emblemático de la teología ascargortiana y concepto prístino catedralicio en su idea de triunfo.

La prioridad de Ascargorta por la representación de la Concepción de María en el Arte es patente por la significativa presencia de este tema en su colección privada (Inmaculada del oratorio de la Catedral o de la Colegial de San Cecilio, sendas de Alonso Cano) así como en su propio mecenazgo (Inmaculada de la Real Chancillería, de Risueño). Sin embargo, más allá del gusto personal, hay que considerar algunos rasgos biográficos del prelado que refrendan su preferencia inmaculista: el más evidente se refiere a su condición de canónigo sacromontano, pero será su propio desempeño de la cátedra de Escoto en la Universidad de Granada la manifestación expresa no solo del conocimiento de la teología del franciscano escocés -defensor inmaculista por excelencia- sino de su compromiso con este dogma cuya doctrina es reafirmada por Paulo V en 1617, siendo refrendada en 1661 en la bula Sollicitudo de Alejandro VII ${ }^{7}$. Ascargorta, tanto por su formación jesuítica en las aulas del colegio de la Compañía de Córdoba como por su condición de prelado granadino, debió conocer y admirar la obra del teólogo jesuita granadino Francisco Suárez (1548-1617), de cuyo aval se servirá para la definición iconológica del retablo de Santiago. La prudencia y el prestigio de Suárez serán definitivos en la validación de las reliquias y apócrifos del Sacromonte que legitimarán la Historia paleocristiana de Granada, reivindicada por Ascargorta. De este

${ }^{6}$ Pomper, A.: "Giovanni Duns Scoto e 1'Inmacolata Concepzione". Comentarium OFMConv, núm. 102. Roma: 2005, pp. 130-150.

${ }^{7}$ Córdoba Salmerón, M.: La Teología Cristiana a través del arte barroco. Granada: Facultad de Teología y Ed. Universidad de Granada, 2019, p. 73. 
modo Suárez, a instancias de D. Pedro de Castro, sancionará subrepticiamente en su "Quaestio theologica" de 1601 la autenticidad de los apócrifos del Sacromonte, defendiendo la posibilidad de la Concepción Inmaculada de María desde la misma tradición apostólica que, supuestamente, había vindicado la misma en un concilio ${ }^{8}$.

Imbricada en los complejos ardides teóricos antedichos se erige la portentosa imagen ecuestre de Santiago en la batalla de Clavijo, incardinada asimismo en la lucha medieval mítica del Apóstol en la Reconquista. La cruzada es culminada por los Reyes Católicos, aludidos por la presencia de la devoción particular de Isabel I, la Virgen del Pópulo, Odighitria que enlaza con el ático temática y simbólicamente. La antigua Iglesia granadina, que milita en la lucha contra la herejía pagana, se coadyuva con la milagrosa protección de Santiago y el consecuente éxito militar de la monarquía castellana. La Iglesia militante se revela victoriosa en el ático del retablo donde se simbolizan las tres virtudes teologales. En el centro, María Inmaculada -símbolo de la $\mathrm{Fe}$ - que vence al pecado desde su misma concepción, estando escoltada por dos nuevos obispos relacionados con la Iglesia de Granada: S. Pedro Pascual, pastor de la Iglesia de Jaén pero martirizado en Granada -trasunto de la virtud teologal de la Esperanza- y Sto. Tomás de Villanueva, obispo de Valencia y también propuesto a la sede granadina, ejemplo de la Caridad.

La reiteración de prelados vinculados a Granada es indiscutiblemente un condicionante del mecenas Ascargorta, constituyendo una sutil evocación del protagonismo del orden episcopal, que él mismo encarna, en el camino de la $\mathrm{Fe}$, desde la persecución paleocristiana hasta el triunfo definitivo del Evangelio en la nueva Granada católica.

Junto a lo antedicho, cabe argüir el hecho de que este retablo supone la consagración no solo del mensaje reformista católico que proclama, sino también la inteligente concepción de un manifiesto plástico diseñado a partir de cuatro imágenes preexistentes y que Ascargorta contextualiza sabiamente en un argumentario de sobresalientes calidades estéticas y sólidas bases teóricas, con el concurso de la escultura de José y Diego de Mora y, por supuesto, con la pintura de su predilecto José Risueño.

\footnotetext{
${ }^{8}$ Martínez Medina, F. J.: “La Inmaculada Concepción en los libros plúmbeos de Granada: su influjo en el Catolicismo contrarreformista”. Magallánica, Revista de Historia Moderna, núm. 3 / 5 (dossier). Mar del Plata: Universidad Nacional de Mar del Plata (Argentina), 2016, pp. 27-28.
} 


\section{El San Cecilio de José de Mora. "La extensión de su rezo"}

Siguiendo la misma inspiración ideológica que concibe la Catedral y la propia Archidiócesis granadina como adalid triunfal en un cristianismo moderno, cabe mencionar la imagen de San Cecilio que a principios de 1704 (el 30 de enero ya consta la donación según acta capitular) el escultor José de Mora entrega al cabildo, oportuna dádiva de un anónimo donante "para que se manifestase y sirviese en la fiesta que se le ha de hacer"'. Resulta este un santo paradigmático en la idea que venimos desarrollando de una nueva nación unida en el triunfo de la $\mathrm{Fe}$, asimilada por el arzobispo Ascargorta para el que de hecho promoverá un rezo propio entre 1702 y $1703^{10}$, una vez conseguida la concesión por el papa Clemente $\mathrm{XI}^{11}$ para el próximo primero de febrero de 1704. El 17 de octubre de 1708 el arzobispo promocionará una delegación en Roma "ante su santidad y sagrada congregación de ritos y pidan y supliquen se conceda extensión de el rezo del señor San Zezilio, primer Arzobispo y Mártir que fue de esta ciudad y Patrón della para todas las demás ciudades y villas y lugares de estos Reynos de España"12.

El fomento del culto al primer obispo de Granada, sin duda alguna, fue favorecido por el propio arzobispo dado que, además del culto propio ya fijado para el primer día de febrero, se determinó, en cabildo de 16 de octubre de 1703, que esa primera festividad canónica del santo mártir se prolongara durante los tres días siguientes, con manifiesto eucarístico en jubileo de las cuarenta horas, incluyendo también procesión.

$Y$ assí mismo se determinó que el último día por la tarde se hiciese procesión fuera de la Santa Yglesia, llevando la efigie del santo a la Yglesia y estación a donde después el cavildo señalara; y que la efigie de señor San Zezilio que está en el altar de nuestra señora de la Anti-

${ }^{9}$ A. C. G. Actas de cabildo, Libro XX, f. 57 v.

${ }^{10}$ El canónigo comisionado del cabildo, José Eugenio Fernández de Luque, va a viajar a Roma para obtener finalmente del papa Clemente XI un rezo propio en la festividad de San Cecilio. Don Martín de Ascargorta autorizará la solemne celebración de la primera misa con el nuevo rito que tendrá lugar el 26 de septiembre de 1703.

${ }^{11}$ López-Guadalupe Muñoz, J. J.: "En la estela de Cano. José de Mora y sus contextos". Gila Medina, L. y Herrera García, F. J. (coord.): El triunfo del Barroco en la escultura andaluza e hispanoamericana. Granada, Editorial Universidad de Granada, 2018, p. 198.

${ }^{12}$ A. H. D. G. Caja 39, 1779 F, f. 100 (2).

Esta rehabilitación definitiva al culto de San Cecilio, promovida por don Martín y que parte de sus deseos de fomentar su devoción desde 1702, supone soslayar el cuestionamiento de la existencia del varón apostólico tras el decreto de Inocencio XI en 1683 que consideraba falsas las reliquias del Sacromonte. 
gua se renovase y compusiese para que en la solemnidad de dichos 4 días estubiese colocada en la Capilla maior para maior devoción de los fieles ${ }^{13}$.

En aras de una mayor solemnidad de festividad tan señalada en la historia diocesana de Granada, a don Martín de Ascargorta no debió satisfacerle la imagen del santo patrono de Rojas ${ }^{14}$ y probablemente debió influir en la hechura de una nueva imagen que será la donada a 30 de enero de 1704, en las vísperas de la celebración de la primera fiesta canónica de San Cecilio ${ }^{15}$. Tal donación consta como realizada por un "devoto" anónimo en acta capitular aunque López-Guadalupe apunta al propio comisionado José Eugenio Fernández de Luque -adalid del culto a San Cecilio- quien, tras volver de Roma con la notable empresa concedida del oficio propio de San Cecilio por Clemente XI, pudo encargar esta obra al escultor José de Mora. Cabe colegir que el criterio de don Martín no debió soslayarse en tal menester pues, seguro conocedor de la obra del bastetano, decidiría sin duda a su favor para realizar la nueva talla ${ }^{16}$; obra que, a la postre, conformaría el corpus iconográfico de una de las creaciones más elocuentes no solo del mecenazgo del prelado sino también considerando los axiomas ideológicos de su pontificado en Granada. Don Martín debió conocer y admirar el Arte del prestigioso José de Mora por sus frecuentes retiros espirituales en la Cartuja; avalando su estimación posteriormente cuando el propio cabildo catedralicio le encomienda la tasación de unas pinturas en 1712, junto con Vicente de Cieza y José Risueño, amén de ser supervisor del proyecto que diseña Hurtado Izquierdo, a instancias de Ascargorta, para la iglesia del Sagrario ${ }^{17}$.

A juicio de López-Guadalupe, este simbólico encargo resulta la piedra angular para la definición de un programa iconológico en la Catedral durante el pontificado de Ascargorta que, partiendo del retablo de la Virgen de la Antigua, hasta el del Triunfo de Santiago, valora un profundo conocimiento de la Historia de Granada, de un pasado cristiano que enlaza el mensaje triunfal de la Puerta del Perdón de Siloe, por la girola (original panteón dinástico) hasta

${ }^{13}$ A. C. G. Actas de cabildo, Libro XXI, f. 44 v.

${ }^{14}$ En acta de cabildo de 21 enero de 1704 se mandaba que "se renovase y compusiese" la imagen de S. Cecilio del retablo de la Antigua -de Pablo de Rojas- con vistas a su inminente culto. A. C. G. Actas de cabildo, Libro XX, f. 56 r.

${ }^{15}$ Gallego Burín, A.: José de Mora. Granada: Universidad, 1988, p. 187.

López-Guadalupe Muñoz, J. J.: José de Mora. Granada: Comares, 2000, pp. 121-122.

${ }^{16}$ Este hecho apuntaría hacia la predilección de Ascargorta por el Arte pictórico de Risueño, prevaleciendo en su estimación los Mora y Duque Cornejo en la escultura.

${ }^{17}$ Gallego Burín, A.: El Barroco granadino. Granada: Comares, 1987, p. 140. 
la puerta de acceso a la Capilla Real: se reivindica el pasado cristiano de Granada y el sentido triunfal de la Catedral.

Esta significativa escultura de San Cecilio pudo encargarse a José de Mora entre octubre y noviembre de 1703, al regreso de Fernández de Luque de Roma, para ser definitivamente depositada "en la capilla de Santiago, en el sitio del cuadro de san Juan de Dios"18, según acta de cabildo de seis de febrero de 1704.

Desde un punto de vista cultural e iconográfico el San Cecilio, de vibrante solución formal, que José de Mora concibe va a reunir tres condiciones que lo definen con carácter singular: es depositario del antiguo acervo devocional de la ciudad, tiene un estudio plástico que permite que sea procesionado y goza de un concepto del pathos que entronca fácilmente con las demandas devocionales de la época. La inventiva de Mora idea para el santo varón una composición inestable de tendencia ascensional, perfectamente integrada en el retablo, marcada por la mitra -en correspondencia con el San Gregorio-que en diagonal imaginaria converge en la Concepción del ático. Es una imagen dramática, de rostro extático casi doliente, que parece preludiar su martirio. La concurrencia compositiva en el retablo desde 1707 con el San Gregorio de Elvira, de Diego de Mora, parece valorizar -en aparente rivalidad en la simetría del primer cuerpo- a este último por su excepcional calidad.

\section{El Triunfo de Santiago o Triumphus Fidei}

La construcción de esta "máquina barroca" en el determinado emplazamiento del arco antecedente a la portada de la Capilla Real resulta especialmente significativa pues culmina una peregrinación de alto valor simbólico desde la Puerta del Perdón, iniciándose en la capilla de la Virgen de la Antigua para, transcurriendo por toda la girola, terminar en el acceso a la Capilla Real. También este "itinerario del triunfo de la Fe" podía discurrir a través del crucero, teniendo inmediatas las capillas de la Virgen de la Antigua y del Triunfo de Santiago ${ }^{19}$. En el espacio culminante de este significativo peregrinaje desde

${ }^{18}$ A. C. G. Actas de cabildo, Libro XX, f. 58 v.

${ }^{19}$ La Capilla Real, coherentemente con los postulados historicistas defendidos por Ascargorta y dada su vital significación en el argumentario iconológico ideado por el prelado, no estará al margen de su munificencia, siendo dotada -a pesar de "tener su fábrica aparte" y de que "no ay exemplar que otro prelado aya dado cosa alguna", según Gómez de Vega- con un "ornamento blanco de tela de oro, que se regula en cinco mil reales [...], seis mil para una colgadura de terciopelo, que sirve el Jueves Santo en el Altar mayor, mas tres frontales de piedra que costaron dos mil y quatrocientos reales. Asimismo vistió dos vezes doze Acólitos de dicha Capilla, haziéndoles sotanas de paño y sobrepellizes". GómEz DE VEGA, C.: Op. cit., p. 40. 
la devoción de los Reyes Católicos -representada en la Virgen de la Antigua- hasta su lugar de enterramiento en la real capilla, el prelado encargará el retablo del Triunfo de Santiago -evidente evocación a la gesta real auxiliada por el concurso providencial del Apóstol-, en julio de 1704. No obstante, dicho retablo no se contratará hasta casi tres años más tarde, periodo en el que se definirán sus valores iconológicos. Ergo, la donación por Fernández de Luque y el propio arzobispo de la imagen de San Cecilio, en el momento de la constitución en Granada de un culto propio al santo patrón, la llegada de Hurtado Izquierdo en 1705 para la realización de las trazas de la nueva iglesia del Sagrario ${ }^{20}$, por deseo del propio Ascargorta, y el legado de la imagen de la Inmaculada por parte del racionero Miguel Fonseca, posible obra de Pedro de Mena, van a ser elementos decisivos en la conformación de este retablo, levantado también en honor de las principales devociones personales de don Martín.

La retórica tardobarroca arropa a una serie de imágenes de notables valores simbólicos individuales pero que, en un elaborado diálogo retablístico, cobran un protagonismo global en una gran escena donde se arguye el origen cristiano del Reino de Granada (San Gregorio de Elvira) y el martirio por la Fe (San Cecilio y San Pedro Pascual), la Caridad como uno de los valores íntimos del prelado en uno de los santos de su devoción, Santo Tomás de Villanueva, y el triunfo definitivo de la Fe (Santiago en Clavijo, Inmaculada, Virgen del Pópulo). La elección y disposición de cada uno de los lienzos e imágenes que conforman el corpus iconográfico del retablo (algunos preexistentes como el S. Cecilio, el Santiago, la Virgen del Pópulo o la Inmaculada) obedeció inexcusablemente al criterio de don Martín de Ascargorta.

La maestría de Hurtado Izquierdo va a permitir la acertada combinación de tales elementos iconográficos, de fuerte significación individual, en un discurso decorativo propio de la época que, además, se adecúa al limitado espacio del que se disponía. Hurtado desafía el estrecho margen espacial aunando huecos y elementos parlantes de mayor volumen en una sabia com-

${ }^{20}$ Se ha documentado una relación epistolar de don Martín de Ascargorta siendo deán de la Catedral con el cardenal D. Pedro de Salazar y Gutiérrez de Toledo -obispo de Córdoba (1686-1706) y antecesor en la sede salmantina de Ascargorta (1681-1686)- en enero de 1687, según menciones en carta al arzobispo Ríos fechada en 28 de enero, donde don Martín da cuenta de los asuntos del cabildo. Inferimos pues que el propio cardenal recomendara a Ascargorta, ya arzobispo de Granada, a Hurtado Izquierdo en 1705 después de la brillante intervención del artista lucentino en la Capilla de Santa Teresa de la Catedral cordobesa, culminada en 1703. Asimismo podría relacionarse la participación de José de Mora en dicha capilla del cardenal a partir de la hechura del San Cecilio en el retablo del Triunfo de Santiago de Granada y fuera recomendado directamente por Hurtado y el propio Ascargorta al cabildo cordobés para el ornato de la mencionada capilla entre 1704 y 1705.

A. H. D. G. Leg. 121 F (A), s/f. 
binación que armoniza el prodigio ornamental con la rectitud de repisas y cornisas mixtilíneas de cada uno de los cuerpos. El lenguaje barroco se materializa en su plenitud en esta magna "máquina" al servicio de la exaltación de Santiago, ubicado en la calle central de doble proporción a las laterales. La poética barroca asimila equilibradamente cada una de las obras que componen el retablo sin que ninguna de ellas quede ahogada en la profusión decorativa del mismo.

El volumen de las esculturas del primer cuerpo -sustentado sobre banco de jaspe ${ }^{21}$-, más próximo al observador, es compensado en el ático mediante la construcción de un pequeño camarín para la Inmaculada, que contrasta con el resalte de los dos paramentos de las calles laterales donde se ubican las pinturas ovales de San Pedro Pascual y Santo Tomás de Villanueva. El interesante juego de claroscuros, permitido por la combinación de volúmenes entre cuerpos y calles, disminuye la sensación de límite espacial que, en efecto, está condicionado por el espacio arquitectónico. Igualmente resulta digno de mención el mesurado contraste que se evidencia en esta obra entre la decoración orgánica ampulosa de ménsulas y remates con lo geométrico de cornisas y repisas. Esta feliz combinación arropa con equilibrio esculturas de gran monumentalidad y pinturas en un resultado canónico al igual que innovador, como anteriormente mencionábamos.

López-Guadalupe valora este retablo como renovador en la trayectoria creativa de Hurtado al concebir una idea con unos parámetros arquitectónicos más ponderados y, ergo, más pictórico y adecuado al limitado emplazamiento del mismo. A juicio del citado profesor son cuatro los rasgos que deciden la innovación del retablo y que serán recurrentes en la retablística del siglo XVIII: el uso del estípite, la profusión ornamental, la desaparición de la estructura arquitectónica y el concepto efectista de los pabellones del ático ${ }^{22}$.

La hechura del retablo se materializa entre marzo y octubre de 1707, pagándose por él 16000 reales más 100 ducados y 400 reales al tallista Juan de la Torre. En junio de 1708 ya estaba montado y colocado, cuando se menciona la necesidad de comenzar su dorado. Sin embargo no consta hasta el 18 de noviembre de 1712 cuando el arzobispo aboga por comenzar su dorado a cargo de la mesa arzobispal ${ }^{23}$, que finalmente realizará el maestro dorador y

21 "Assí mismo donó dicho Ilustrísimo Señor dos mill trescientos y sesenta reales para pagar el banco de jaspe que se puso a el retablo de Señor San Tiago”. A. H. D. G. Consejos, Leg. 15819, pza. 1.1., f. $134 \mathrm{v}$.

${ }^{22}$ López-Guadalupe, J. J.: "La arquitectura de retablos". Gila Medina, L. (coord.): El Libro de la Catedral de Granada. Granada: Cabildo Metropolitano, 2005, vol. 1, pp. 506-507.

${ }^{23}$ López-Guadalupe documenta este contrato en el Archivo Histórico del Arzobispado de Granada, publicado en ibídem, p. 1401. Finalmente don Martín pagará a Pedro Romero la cantidad de 
estofador Pedro Romero. En el contrato se especifican una serie de pautas que pretenden armonizarlo con el marco arquitectónico encalado, contemplando el bruñido de algunas zonas en blanco albayalde, detalle que evita la homogeneización cromática del conjunto, dotándolo de un mayor dinamismo visual y un adecuado encaje al contexto.

El vasto valor simbólico de este retablo, significante del triunfo de la $\mathrm{Fe}$, sintetiza el propio carácter de toda la Catedral, por lo que su relevancia en el alhajamiento del templo es especialmente significativo. Mediante una equilibrada integración de esculturas y lienzos, de fuerte carácter individual, se elabora un discurso teórico incidente en el fideísmo triunfal, donde cada una de las obras cobra una nueva dimensión global a favor de esta idea.

La escultura ecuestre titular del retablo de Santiago ${ }^{24}$ representa el milagro en que el apóstol se aparece en la legendaria Batalla de Clavijo -trasunto mítico de la Batalla de Albelda- y ayuda al ejército de Ramiro I a derrotar a las tropas de Abderramán II el 23 de mayo de $844^{25}$. La escultura de Santiago matamoros -concebido con una iconografía de aristócrata castrense, despojada de toda retórica propia de un personaje sagrado- era una imagen preexistente, obra de Alonso de Mena, encargo del cabildo de la ciudad el 5 de febrero de $1638^{26}$ para regalo al templo mayor de la ciudad, y que presidía la capilla central de la girola catedralicia desde 1640, dedicada a su advocación ${ }^{27}$.

En acta capitular de 8 de julio de 1704 don Martín manifiesta que quiere cambiar la imagen del Sr. Santiago para que pueda tener un mayor culto en el sitio y arco que hay más debajo de Nuestra Señora de la Guía, adornándolo

15.000 reales por el dorado del retablo "cuia porción cedió dicho Ilustrísimo Señor en efectos de partidas sin cobrar de su Mesa Arzobispal”. A. H. N. Consejos, leg. 15819, pza. 1.1.

${ }^{24}$ Esta obra afortunadamente se salvó del expolio francés a pesar de estar incluida, junto con el tondo de la Encarnación de Risueño, en el inventario de Quilliet para depositar en la Cartuja granadina con destino al nuevo "Museo josefino" de Madrid. Antigüedad del Castillo, M. D.: "Un pleito artístico: Granada y el Museo Josefino". Espacio, tiempo y forma, serie xVII, Historia del Arte, 1. Madrid: Universidad Complutense, 1988, p. 259-286.

${ }^{25}$ Martínez Díez, G.: El Condado de Castilla (711-1038): La historia frente a la leyenda, vol. 1. Valladolid: Ed. Marcial Pons, 2005, p. 143.

${ }^{26}$ Sánchez-Mesa Martín, D.: "La escultura devocional". Gila Medina, L. (coord.): El Libro de la Catedral de Granada. Granada: Cabildo Metropolitano, 2005, vol. 1, p. 455.

${ }^{27}$ Gila Medina, L.: “Alonso de Mena y Escalante: escultor, ensamblador y arquitecto”. Gila Medina, L. (coord.): La consolidación del Barroco en la escultura andaluza e hispanoamericana. Granada: Universidad, 2013, p. 59.

Alonso de Mena recibió del cabildo de la ciudad 150 ducados por esta obra siendo trasladada en solemne procesión a la Catedral el 24 de julio de 1640 -según refiere Henríquez de Jorquera (HeNRíqueZ DE JoRquera, F.: Anales de Granada, Granada: Universidad, 1987, vol. 2, p. 865-866.)-. 
decentemente a su costa ${ }^{28}$. Este deseo del prelado revela dos extremos relevantes en su concepción iconológica de la Catedral: su preocupación creciente por la exaltación del culto al Apóstol -que culminará con el diseño y construcción del retablo tres años más tarde- $y$, sobre todo, el diseño de un itinerario simbólico desde la Puerta del Perdón por la girola hasta el acceso a la Capilla Real, basado en el axioma del Triumphus Fidei.

D. Martín profesará una rendida devoción al Patrón de España ${ }^{29}$ expresándose, por ejemplo, en el aniversario y memoria de misas perpetuas a Santiago y San Juan Gualberto que fundará en el Sacromonte el 25 de julio de $1707^{30}$. Se atestigua, igualmente, tal veneración a Santiago en la donación -según acta de cabildo de 21 de junio de 1709- de diez y seis pesos de plata bieja para la celebración de vigilia, misa y sufragios tras su muerte, mandando además que se celebraran en la capilla de San Dionisio del colegio o en la capilla de Señor San Tiago de las sagradas cuebas, por la especial devoción que dicho Señor arzobispo tiene a este Santo Apostol ${ }^{31}$.

Volviendo a la imagen de Santiago, insistimos en su acompañamiento -pleno de significado- en el primer cuerpo del retablo de la anteriormente analizada imagen de San Cecilio de José de Mora, que es aparejada por un

${ }^{28}$ A. C. G. Actas de cabildo, Libro XX, f. 26 v.

${ }^{29}$ Casualmente don Martín de Ascargorta será ordenado presbítero en la entonces capilla de Santiago de la Catedral el 11 de junio de 1661 -central de la girola, presidida por la escultura ecuestre del Apóstol, de Alonso de Mena-, víspera de San Juan Gualberto, a quien también dedicará memoria de misas. A.H.D.G. Libro Archivo Caja 25 (Libro de Buen Gobierno de Argaiz). ff. 221 v. - 223 v.

Gómez de Vega justifica la memoria de misas a San Juan Gualberto relatando un interesante episodio en el que en 1712 Felipe V, "dadas las estrecheces de la monarquía” pidió donativo al clero. El cabildo de la Catedral lo trasladará al arzobispo que, manifestado su lealtad al Rey, supedita dicho donativo a la voluntad del Papa. Esta circunstancia generó un conflicto en algunos capitulares y en la Corte incluso "ordenándose Decreto para extrañar de estos dominios al arzobispo". Finalmente, será el provisor y también canónigo del Sacromonte, D. Cristóbal Damasio, quien asuma las consecuencias siendo llamado a Bayona, para ser posteriormente restituido de su dignidad en Granada que ejercerá hasta la muerte de Ascargorta en que es nombrado Vicario en Madrid. Según Gómez de Vega en 1714 -en protesta por la restitución de Damasio- se redactó por parte de dos prebendados del cabildo un memorial contra dicho provisor "mas lleno de imposturas que de palabras" sin más consecuencias. Este hecho conflictivo revela no solo el prestigio de Ascargorta en la Corte, que no tomó represalias contra el prelado, sino la fundación de la memoria a San Juan Gualberto porque "fue santo perdonador de su enemigo". Por supuesto, el donativo real fue satisfecho con "doze mill quatrocientos y veinte reales que se dieron al Señor Rey Don Phelipe Quinto por razón de donativos en los dos años de 1712 y 1713, cuia cantidad se saco del caudal de las cesiones". A.H.N. Consejos, leg. 15819, pza. 1.1, f. 135 v.

Gómez de Vega, C.: Op. cit., pp. 53-57.

${ }^{30}$ A. S. M. Leg. 253, Libro 42, ff. 1 r. - 2 v.

${ }^{31}$ A. S. M. Libro de actas de cabildo de 1709, f. 315. 
San Gregorio de Elvira, de Diego de Mora de 1707. Se trata ésta de una obra sufragada gracias a una dotación previa de Ascargorta de sesenta mil reales para la hechura del retablo de Santiago, de los cuales se destinan dos mil reales que se pagan a Diego de Mora para la realización de esta talla, más setenta y ocho por la peana y traslado de la imagen desde el taller a la Catedral ${ }^{32}$. Llama la atención el que Ascargorta prefiera el Arte escultórico de Diego de Mora sobre el de su protegido Risueño para el menester de la hechura del S. Gregorio. Probablemente el arzobispo buscara la armonización estilística con el preexistente San Cecilio de José de Mora, al que debía acompañar en el retablo, y con la Inmaculada, que acababa de ser restaurada por Diego de Mora, y recurriera pues al prestigio de esta saga familiar en el Arte de la escultura, prefiriendo a Risueño siempre en la pintura, que en todo caso será su Arte favorito.

Comparte este San Gregorio con el San Cecilio la tendencia ascensional en su concepto, subrayada por la verticalidad de la mitra y el báculo, aunque esta aportación de Diego se resuelve de manera más dinámica y menos envarada que la del primer obispo. Aunque no constan directrices del arzobispo para la hechura de esta imagen se hace evidente la inspiración del autor en la imagen preexistente de San Cecilio, con quien comparte soluciones polícromas similares. Más allá de sus peculiaridades formales me interesa destacar el profundo valor simbólico de la elección de este santo para el retablo, en un discurso iconográfico que se repite en el retablo de la Virgen de la Antigua. Santiago, milagroso corresponsable de la reconquista; San Cecilio, discípulo de Santiago, mártir y primer obispo de Granada y San Gregorio de Elvira, obispo iliberitano y escritor del siglo IV. Este discurso iconográfico pretende entroncar la tradición cristiana granadina en los mismos albores del cristianismo, una Fe estoica con sólidos teóricos como San Gregorio, conocido asimismo por el propio Isidoro de Sevilla ${ }^{33}$.

Preside el ático del retablo otra de las obras preexistentes, la Inmaculada Concepción. Esta nueva recreación del misterio concepcionista es heredera directa de los modelos canescos tan difundidos en la estatuaria granadina de los siglos XVII y XVIII. Según se acredita en acta capitular de 22 de mayo de $1705^{34}$, la Inmaculada fue donada por el racionero Miguel Fonseca, comisionándose al canónigo Abad para que hiciera las diligencias oportunas y com-

${ }^{32}$ Palomino Ruiz, I.: Diego de Mora. Vida, obra e influjo de un artista de saga. Granada: Universidad, 2017, p. 309.

${ }^{33}$ Sotomayor, S.: Historia de la Iglesia en España. I. La Iglesia en la España romana y visigoda. Siglos I-VIII. Madrid: Biblioteca de Autores Cristianos, 1979, pp. 218-232.

${ }^{34}$ A. C. G. Actas de cabildo, Libro XXI, ff. 125 v. - 126 r. 
ponerla más a su gusto. Finalmente, en enero de 1707 dicha "composición" ya está realizada por Diego de Mora, solicitándose permiso para ser trasladada desde el taller de Mora a la Catedral. Isaac Palomino documenta que tal excesivo periodo de tiempo para un mero aderezo se debió a una restauración $\mathrm{y}$, previsiblemente, a un repolicromado completo, recibiendo el artista por tal trabajo la cantidad de 200 reales $^{35}$. La corona fue realizada por el platero catedralicio Andrés Romero en 1707 y la media luna en 1713, a petición del cabildo ${ }^{36}$.

Considero inquietante para la atribución tradicional a Risueño ${ }^{37}$ que, dado el prestigio reconocido y afecto y consideración personal del prelado por el artista, en aquellas horas de 1705, periodo de plena eclosión creativa del autor, la obra se encontrara tan presuntamente deteriorada y que, además, su restauración y, más significativo aún, su repolicromado no corrieran a cargo de su supuesto autor José Risueño. Por todo ello y a tenor del propio análisis formal de la escultura -actualmente ya poco explícita de su estado anterior a la intervención de Mora-convengo que efectivamente -como sostiene el profesor León Coloma ${ }^{38}$ - esta Inmaculada podría ser una creación más temprana, del escultor Pedro de Mena y Medrano ${ }^{39}$, relacionando su monumentalidad con la Purísima de Alhendín y de filiación formal y compositiva canesca. Pienso que podría datarse coetánea a la de Alonso Cano del facistol y a la citada de Alhendín, en torno a 1656 -inserta en los últimos años de Mena en Granada, antes de su partida a Málaga en 1658 y coincidente con su etapa creativa próxima a Cano-. León Coloma advierte sobre un modismo personal de Mena que explicita su gubia: la disposición en paralelo de los dedos anular

${ }^{35}$ Palomino Ruiz, I.: Op. cit., p. 308.

${ }^{36}$ A. C. G. Actas de cabildo, Libro XXII, f. 198 r.

${ }^{37}$ Gómez-Moreno Martínez, M.: "La Inmaculada en la escultura española”, Miscelánea Comillas, núm. XXIII, 1955, p. 391; Gómez-Moreno GonzÁlez, M.: Guía de Granada. Granada: Universidad, ed. facsímil de 1998, p. 278; Orozco Díaz, E.: "Alonso Cano y su escuela”. Centenario de Alonso Cano. Catálogo. Granada: Caja General de Ahorros, 1969, p. 278. Gallego Burín, A.: Granada. Guía..., p. 272. SÁnchez-Mesa Martín, D.: José Risueño: escultor y pintor granadino (1665-1732). Granada: Universidad, 1972, p. 180, y en “La escultura devocional”. GiLA MedinA, L. (coord.): El libro de la Catedral de Granada. Granada: Cabildo Metropolitano, 2005, vol. 1, p. 497; López-Guadalupe MuÑoz, J. J.: "La arquitectura de retablos", vol. 1, p. 505 y Peinado GuZmán, J. A.: Controversia teológica. Devoción popular. Expresión plástica: La Inmaculada Concepción en Granada. Granada: Universidad, 2011, p. 924.

${ }^{38}$ León Coloma, M. A.: "La escultura en la Catedral de Granada". Calvo Castellón, A. et al. (coord.): El Libro de la Catedral de Granada. La Capilla Real y la Iglesia del Sagrario. Granada: Cabildo Metropolitano, 2007, p. 296.

${ }^{39}$ La autoría de Pedro de Mena ya es apuntada por el siempre agudo D. Manuel Gómez Moreno en Gómez-Moreno, M : Guía... p. 278. 
y corazón, interrumpiendo así la cadencia angular del resto de los dedos. Este modismo lo detecta dicho investigador al menos en seis inmaculadas más de Mena, como la de la parroquial de Alhendín o la de de Ogíjares ${ }^{40}$, y efectivamente puede sugerir al Arte de Mena. Sin embargo, y a pesar de no poderse observar con la policromía original, su monumentalidad, el concepto de "pathos" austero en la Virgen -de connotaciones próximas a un hieratismo cuasi áulico, tan íntimo de Mena en sus concepciones-, la personal esfera terrestre sobre la que María se yergue o la abstracción de los frunces de túnica y manto son rasgos que parecen avalar esta atribución, sumado a otras características formales como la solución de las cabezas de querubes de la base o los propios estilemas faciales que apuntan efectivamente -a mi juicio- al Arte del escultor granadino. No obstante, hay que barajar otra opción y es que pudiera deberse a algún seguidor de Mena en Granada, como Juan Puche. La artificiosidad de los plegados, de profundo contraste lumínico, parece apuntar a alguien que también fuera buen conocedor de Cano, como es el caso de Puche. Sin embargo, en apariencia el juego plástico, de volúmenes muy marcados y contrastados, no concuerda exactamente ni en la línea de Cano ni en la de Mena.

Desconocemos el lugar donde debió estar situada esta imagen de tamaño canónico, tal vez en algún emplazamiento a la intemperie relacionado con el racionero Miguel Fonseca -probable poseedor de una colección artística-, pero su deterioro aconsejó una restauración que parece ajena al arzobispo Ascargorta, que entiendo habría propiciado una intervención de su artista protegido y pintor predilecto José Risueño.

Más allá de la controvertida autoría de la Inmaculada no debemos soslayar el trascendental significado que su presencia confiere en el discurso temático del retablo. La Inmaculada, ergo, se erige como adalid simbólico del trimphus Fidei, armonizándose asimismo en el ideario reformista católico ascargortiano que valora la preeminencia de María como mujer invicta, calificada como "amplificatio" 41 durante el siglo XVII y vindicada como figura clave en la soteriología desde Trento. Frente a los reformadores que querían limitar la trascendencia de la madre de Jesucristo a un ministerio secundario en la soteriología, la figura de la Virgen será reivindicada desde Trento especialmente por órdenes religiosas como la de San Francisco o la Compañía de Jesús ${ }^{42}$. A dichas órdenes estará vinculado Ascargorta desde su primera formación en el Colegio de la Compañía de Córdoba, y con los franciscanos por diversos lazos familiares. Además, su pertenencia a la Universidad de Granada -defensora

\footnotetext{
${ }^{40}$ León Coloma, M. A.: Op. cit., p. 296.

${ }^{41}$ Córdoba Salmerón, M.: Op. cit., p. 69.

${ }^{42}$ Ibidem.
} 
del "votum sanguinis"- y su condición de catedrático de Escoto avalan su compromiso con esta nueva visión de María, acervo que recoge el especial simbolismo de esta Concepción del retablo de Santiago.

Los lienzos de San Pedro Pascual y Santo Tomás de Villanueva que cortejan la imagen de la Inmaculada en el ático del retablo, obras de José Risueño, son un encargo 'ex profeso' al artista granadino, tal como ha documentado León Coloma, recibiendo el artista granadino la exigua cantidad de 450 reales por los mismos el 7 de septiembre de $1707^{43}$. Este dato viene a refutar los vaivenes historiográficos que habían apuntado al pintor y eclesiástico Benito Rodríguez Blanes como autor.

La autoría de estos lienzos, aunque Gómez-Moreno ya apuntara en 1892 a José Risueño ${ }^{44}$, ciertamente ha sido objeto de un debate historiográfico, especialmente el San Pedro Pascual pues, quizá debido a la dificultosa visión de las obras que no permitió un análisis óptimo y la diferente resolución de los mismos, ha sido asignado por Gallego Burín ${ }^{45}$ y Sánchez-Mesa ${ }^{46}$ al Arte de Benito Rodríguez Blanes.

Ambas obras pertenecen al periodo creativo de madurez de Risueño y están resueltas de una manera constrastada ya que la actitud dinámica del obispo mercedario en un elegante semiescorzo nada tiene que ver, en apariencia, con la serenidad manifiesta en el santo agustino. Ambos se representan con su iconografía más solemne, optando Risueño por figurarlos revestidos de su dignidad episcopal con capa pluvial, mitra, pectoral y báculo pastoral ${ }^{47}$, una sutil evocación al comitente Ascargorta ${ }^{48}$ y en coherencia con la estatuaria

${ }^{43}$ León Coloma, M. A.: "Mentores frente a comitentes: la dotación iconográfica de la Capilla mayor de la Catedral de Granada en el último tercio del siglo XVII", en Ramallo AsEnsio, G. (coord.): El comportamiento de las catedrales españolas. Del Barroco a los Historicismos. Murcia: Universidad, 2003, p. 340, nota 99.

La consulta en el A. C. G. de los Libros de hacienda de la Catedral 1707-1737 (varios 64, f. 4 r.), referidos por León, arroja la errata de la publicación de tal dato, siendo 450 reales la cantidad pagada por sendos lienzos y no 1450 como aparece publicado. Resulta curioso que Risueño cobrara 200 reales por el repolicromado completo de la Inmaculada (v. n. 296), desvelándose de la comparación de estas cifras un contrastado caché entre ambos artistas, con una valoración mayor de Risueño en detrimento de Diego de Mora.

${ }^{44}$ Gómez-Moreno, M.: Guía..., p. 278.

${ }^{45}$ Gallego Burín, A.: Granada. Guía...., p. 272.

${ }^{46}$ Sánchez-Mesa Martín, D.: José Risueño..., p. 308.

${ }^{47}$ Contrasta el Santo Tomás de Villanueva con el que, seguramente, Ascargorta regala a la iglesia del hospital de la Caridad y Refugio, de iconografía más austera y civil.

${ }^{48}$ Se refuerza esta hipótesis por la similitud entre el báculo pastoral de ambos santos con el de Ascargorta, representado en el retrato del Colegio de la Asunción de Córdoba y cuyos cayados o 
del primer cuerpo. Más allá de los análisis formales que estas obras suscitan, quiero subrayar de nuevo que la elección precisa de ambos por el arzobispo Ascargorta para este retablo concreto del Triunfo de Santiago, obedece al pensamiento más profundo del propio prelado: Santo Tomás de Villanueva es una devoción recurrente en los escritos de don Martín porque asimismo representa una de sus virtudes personales más alabadas por sus coetáneos, la liberalidad, el desprendimiento como trasunto de la caridad ${ }^{49}$. El obispo agustino aparece representado con los atributos propios de su dignidad, repartiendo dinero entre los pobres, en una escena arquitectónica que recuerda a la empleada por Risueño en los retratos de Ascargorta. Por su parte San Pedro Pascual fue obispo de Jaén y apresado por los musulmanes de Granada en una de sus visitas pastorales, recibió martirio en Granada donde fallece en 1300. Según su hagiografía destinó el dinero que recibió para su rescate por la Orden Mercedaria y la Iglesia de Jaén a liberar a niños y mujeres, haciendo honor nuevamente a ese valor del desprendimiento máximo hecho caridad, tan representativo de la personalidad de don Martín de Ascargorta. En el obispo mercedario además, por la circunstancia de su cautiverio por los musulmanes granadinos, se evoca nuevamente esa idea agustina del triunfo de la caridad sobre el mal, presente no solo en este retablo de Santiago sino en el mismo concepto de la seo granadina $^{50}$. La presencia iconológica de San Pedro Pascual, María Inmaculada y Santo Tomás de Villanueva constituye asimismo un trasunto plástico de las tres virtudes teologales, simbolizando respectivamente la Fe, la Esperanza y la Caridad. Este discurso simbólico se complementa con la representación de la Iglesia militante del cuerpo inferior, centrada en Santiago y en los obispos de la Historia paleocristiana granadina, Cecilio y Gregorio.

Puede inferirse que la presencia en este retablo de cuatro santos obispos relacionados con el pasado cristiano de Granada, Cecilio, Gregorio, Pedro Pascual y Tomás de Villanueva considero que tienen un significado ambivalente en la medida en que son una vindicación de la muy antigua historia cristiana de la archidiócesis, pertenecen al devocionario personal del comitente y

volutas son elocuentemente parecidos. Igualmente, son semejantes las cruces pectorales de los dos santos y las de los retratos de Ascargorta.

${ }^{49}$ Santo Tomás de Villanueva (1486-1555) renunció al arzobispado de Granada tras propuesta de Carlos I, quizás en periodo vacante tras la muerte de Pedro Portocarrero el 5 de junio de 1526.

Álvarez, L.: "Iconografía e iconología en torno a la figura de Santo Tomás de Villanueva. De Juan de Juanes a Murillo". Iconografía Agustiniana, XI Congreso Internacional de la Orden de San Agustín, Roma: Institutum Historicum Augustinianum, 2001, pp. 491-545.

${ }^{50}$ Sanlés, P.: "Pascual, Pedro". En Q. Aldea Vaquero, T. Marín Martínez y J. Vives Gatell (dirs.): Diccionario de Historia Eclesiástica de España, vol. III, Madrid, Consejo Superior de Investigaciones Científicas, Instituto Enrique Flórez, 1973, p. 1885. 
asimismo legitiman la labor pastoral de la dignidad episcopal representativa de Ascargorta. Este aspecto es respaldado por la preferencia hacia el obispo Santo Tomás sobre San Juan de Dios -santo "local" granadino, excelencia del amor fraterno y de creciente devoción popular en este tiempo- en la representación de la caridad, exigencia probable del comitente que se significa por medio de la simbolización arguyente del orden episcopal. Los cuatro santos obispos acompañados de las monumentales imágenes de Santiago y la Purísi$m a$, de profundo calado hispano, enraízan igualmente ese acervo espiritual del prelado y de la archidiócesis con la tradición católica española.

El carácter historicista del retablo se complementa a la perfección con la inclusión en el mismo de la pintura más antigua conservada en la Catedral, la Virgen de los Perdones o del Pópulo, que se sitúa bajo el dosel que timbra la calle central del primer cuerpo presidida por la escultura ecuestre de Santiago. Francisco de Paula Valladar y Gómez-Moreno ${ }^{51}$ refieren que esta tabla fue regalada por Inocencio VIII a Isabel la Católica que, según la tradición, sirvió como altar portátil de los Reyes en el Real de Santa Fe y "ante la que se dijo la primera misa después de la Reconquista en la Mezquita de la Alhambra" ${ }^{52}$. Esta Odighitria, reproducción de la Virgen del Pópulo de la Basílica de Santa María la Mayor de Roma del siglo V, constituye en el retablo una imagen de acusado valor iconológico pues, efectivamente, "muestra el camino" hacia la Verdad desde la militancia paleocristiana del primer cuerpo hacia el triunfo final de la Fe, que en sentido ascensional se representa en el ático por las imágenes de la Inmaculada, S. Pedro Pascual y Sto. Tomás de Villanueva. Ascargorta, conocedor de la historia de la tabla, con su idea de ubicarla coronando el espacio de Santiago va a asociar -asimismo- el triunfo de la Fe sobre el pecado con la gesta militar de los Reyes Católicos (relaciónese con la misma imagen de Nuestra Señora de la Antigua) y por ende con los primeros tiempos del Cristianismo en Granada. Se establece de esta manera un sutil juego de paralelismos que fusionan el credo con la política, en un concepto nítidamente moderno del Estado a cuya defensa el arzobispo Ascargorta se erige en adalid.

Podemos concluir arguyendo la erección del Apóstol Santiago, para Ascargorta, como emblema piadoso y político que media a favor de la guerra contra el Islam y beneficia la restitución del reino de Granada a la Fe católica. La evocación a esa primitiva Iglesia paleocristiana granadina se realizará por

${ }^{51}$ VAlLADAR, F. DE: Guía de Granada: historia, descripciones, artes, costumbres, investigaciones arqueológicas. Granada: Universidad, 2000.

Gómez-Moreno, M.: Guía..., p. 278.

${ }^{52}$ Ibidem. 
El Arzobispo D. Martín de Ascargorta (1693-1719) y su mecenazgo

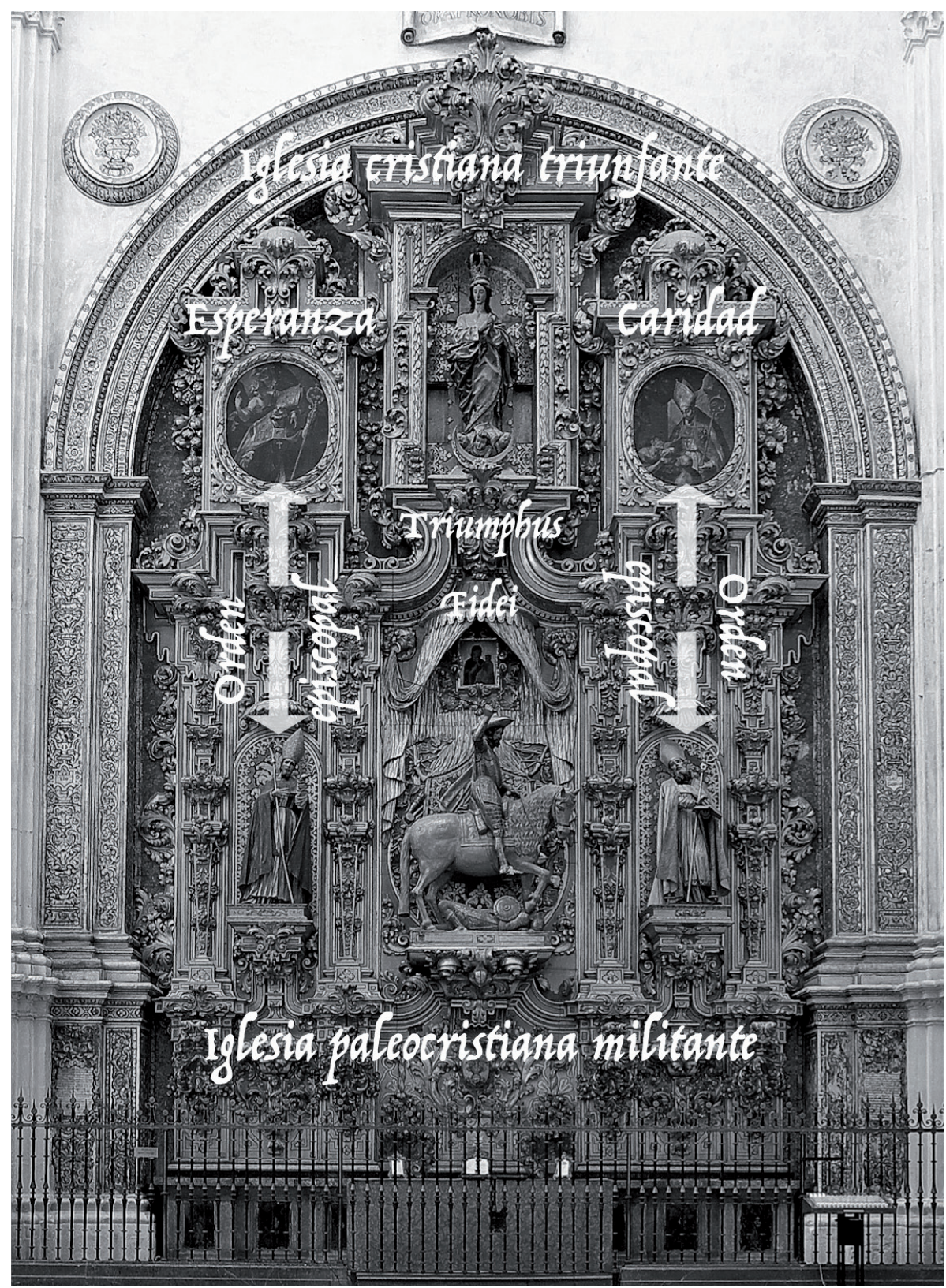

Retablo del Triunfo de Santiago o de la Fe, Hurtado Izquierdo, Catedral de Granada, 1707. 
medio de un fomento cultual a San Cecilio, mártir y primer obispo diocesano, y a San Gregorio de Elvira, sustento teológico prestigioso de dicha Iglesia antigua que sanciona la controvertida existencia del primer mitrado. Las virtudes de Fe (teologal) y Justicia (cardinal), preconizadas en la proclama pétrea de la Puerta del Perdón de Siloe, son asimiladas por Ascargorta, en su mecenazgo a favor de Santiago y la Inmaculada para subrayar y solemnizar el deambulatorio catedralicio (desde el retablo de la Virgen de la Antigua, también promovido por el mitrado), en un ejercicio evocador donde se armonizan la exaltación de la gesta política y militar con el triunfo de la Fe cristiana sobre lo herético, por otra parte modelo representativo de los axiomas más básicos del Antiguo Régimen, la Iglesia y el poder.

\section{Fuentes de archivo consultadas}

Archivo Histórico Diocesano de Granada (A. H. D. G.)

Libro minutario de cartas. Libros Archivo. Caja 24 (1).

Libro Archivo Caja 25 (Libro de Buen Gobierno de Argaiz). ff. 221 v. $223 \mathrm{v}$.

Consejos, Leg. 15819, pza. 1.1., f. 134 v.

Caja 39, 1779 F, f. 100 (2).

Leg. $121 \mathrm{~F}(\mathrm{~A}), \mathrm{s} / \mathrm{f}$.

Archivo de la Catedral de Granada (A. C. G.)

Actas de cabildo

Libro XX, f. 26 v., f. 56 r., f. 57 v., f. 58 v.

Libro XXI, f. 44 v., ff. 125 v. - 126 r., f. 198 r.

Archivo del Sacromonte (A. S. M.)

A.S.M. Leg. 253, Libro 42, ff. 1 r. -2 v.

A.S.M. Libro de actas de cabildo de 1709, f. 315.

\section{Bibliografía consultada}

Álvarez, L.: "Iconografía e iconología en torno a la figura de Santo Tomás de Villanueva. De Juan de Juanes a Murillo". Iconografía Agustiniana, XI Congreso Internacional de la Orden de San Agustín, Roma: Institutum Historicum Augustinianum, 2001.

Antigüedad del CAstillo, M. D.: "Un pleito artístico: Granada y el Museo Josefino". Espacio, tiempo y forma, serie VII, Historia del Arte, 1. Madrid: Universidad Complutense, 1988. 
Córdoba Salmerón, M.: La Teología Cristiana a través del arte barroco. Granada: Facultad de Teología y Ed. Universidad de Granada, 2019.

Gallego Burín, A.: Granada. Guía artística e histórica de la ciudad. Granada: Comares, 1989.

El Barroco granadino. Granada: Comares, 1987.

José de Mora. Granada: Universidad, 1988.

Gila Medina, L.: "Alonso de Mena y Escalante: escultor, ensamblador y arquitecto". Gila Medina, L. (coord.): La consolidación del Barroco en la escultura andaluza e hispanoamericana. Granada: Universidad, 2013, p. 59.

Gómez de Vega y Montalvo, C.: Panegírico historial de la vida y virtudes del Ilmo. Señor Don Martín de Ascargorta. Madrid: Imp. Gregorio Hermosilla, 1722.

Gómez Román, A. M.: "Promoción y mecenazgo artístico del arzobispado de Granada durante el siglo XVIII". Cortés Peña, A. L: Estudios sobre Iglesia y Sociedad en Andalucía en la Edad Moderna. Granada: Universidad, 1999.

Gómez-Moreno González, M.: Guía de Granada. Granada: Universidad, ed. facsímil de 1998.

Gómez-Moreno Martínez, M.: "La Inmaculada en la escultura española", Miscelánea Comillas, núm. XXIII, 1955.

HenríqueZ De Jorquera, F.: Anales de Granada, 2 vols. Granada: Universidad, 1987.

León Coloma, M. A.: "La escultura en la Catedral de Granada". Calvo CasTEllón, A. et al. (coord.): El Libro de la Catedral de Granada. La Capilla Real y la Iglesia del Sagrario. Granada: Cabildo Metropolitano, 2007.

LóPEZ-Guadalupe MuÑoz, J. J.: "El mecenazgo artístico en la Granada del siglo XVIII. La financiación del Arte religioso". Revista del Centro de Estudios Históricos de Granada y su Reino, n. 10-11. Granada: CEHGR, 1996-1997.

José de Mora. Granada: Comares, 2000.

"La arquitectura de retablos". GiLA Medina, L. (coord.): El Libro de la Catedral de Granada. Granada: Cabildo Metropolitano, 2005, vol. 1.

"En la estela de Cano. José de Mora y sus contextos". Gila Medina, L. y Herrera García, F. J. (coord.): El triunfo del Barroco en la escultura andaluza e hispanoamericana. Granada, Editorial Universidad de Granada, 2018, p. 198.

Martínez Díez, G.: El Condado de Castilla (711-1038): La historia frente a la leyenda, vol. 1. Valladolid: Ed. Marcial Pons, 2005.

Martínez Medina, F. J.: "La Inmaculada Concepción en los libros plúmbeos de Granada: su influjo en el Catolicismo contrarreformista". Magallánica, 
Revista de Historia Moderna, núm. 3 / 5 (dossier). Mar del Plata: Universidad Nacional de Mar del Plata (Argentina), 2016.

Orozco Díaz, E.: "Alonso Cano y su escuela". Centenario de Alonso Cano. Catálogo. Granada: Caja General de Ahorros, 1969.

Palomino Ruiz, I.: Diego de Mora. Vida, obra e influjo de un artista de saga. Granada: Universidad, 2017.

Peinado Guzmán, J. A.: Controversia teológica. Devoción popular. Expresión plástica: La Inmaculada Concepción en Granada. Granada: Universidad, 2011.

PompeI, A.: "Giovanni Duns Scoto e l'Inmacolata Concepzione". Comentarium OFMConv, núm. 102. Roma: 2005, pp. 130-150.

SÁnchez-Mesa Martín, D.: José Risueño: escultor y pintor granadino (16651732). Granada: Universidad, 1972.

"La escultura devocional". Gila Medina, L. (coord.): El Libro de la Catedral de Granada. Granada: Cabildo Metropolitano, 2005, vol. 1.

Sanlés, P.: "Pascual, Pedro". En Q. Aldea Vaquero, T. Marín Martínez y J. Vives Gatell (dirs.): Diccionario de Historia Eclesiástica de España, vol. III, Madrid, Consejo Superior de Investigaciones Científicas, Instituto Enrique Flórez, 1973.

Sotomayor, S.: Historia de la Iglesia en España. I. La Iglesia en la España romana y visigoda. Siglos I-VIII. Madrid: Biblioteca de Autores Cristianos, 1979.

Valladar, F. DE: Guía de Granada: historia, descripciones, artes, costumbres, investigaciones arqueológicas. Granada: Universidad, 2000. 